ORIGINAL PROF-2046

\title{
STAPHYLOCOCCUS AUREUS;
}

Prevalence in burns patients.

Dr. Zulfiqar Ali Naqvi, Dr. Qamar Aziz, Dr. Arif Memon

ABSTRACT... Objective: To determine the prevalence of Staph. aureus in burn patients. Setting: Department of Microbiology, Basic Medical Sciences Institute, Jinnah Postgraduate Medical Centre, Karachi. Period: July 2002 to December 2002. Material and Methods: Out of 52 patients 23 (44\%) were found infected by 41 strains of S. aureus in which 10 strains were Methicillin resistant. Results: All Methicillin sensitive and resistant strains were sensitive to Vancomycin and Chloramphenicol. Other effective drugs against MSSA were Imipenem (93.5\%), Cephalothin (77.5\%), Clindamycin (68\%) while MRSA strains were highly resistant to all other drugs. Conclusions: Gram positive heavily colonize the wound at initial days following burn injury. Once Staph aureus specially MRSA establishing in burn unit, it is very difficult to eradicate these bacteria from burn unit. It is therefore all efforts must made to prevent burn patients from infection specially Staph. Aureus infection, by establising infection control team these burn units.

Key words: Burn, Wound, Infection, Staph.aureus, MRSA

\section{Article Citation}

$\checkmark \quad$ Naqvi ZA, Aziz Q, Memon A. Prevalence of Staphylococcus aureus in burns patients. Professional Med J Feb 2013;20(1):139-143.

\section{INTRODUCTION}

Normal skin is effective barrier that prevent penetration of surface bacteria ${ }^{1}$. The devitalized tissue and moist burn is favorable for colonization and proliferation of micro-organisms and subsequent infection, therefore the potential risk of burn wound sepsis persist until complete wound healing ${ }^{2}$.

The systemic immune responses are altered by burning and defect occurs in cellular arm as well as in humoral arm of immunity that result in imbalance in the normal equilibrium between bacteria and host resistance Contamination of the burn wound is the initial and most important mode for the development of sepsis. The other risk factor for burn wound sepsis is prolonged hospital stay that result in nosocomial infection which occurs between patients due to spread of organism by air born, direct contact between patients and indirectly by visitors. Health care workers hands are also major vehicle of transmission of infection. Immuno comprising effects, invasive diagnostic and therapeutic procedure and use of broad spectrum antibiotic also contribute to develop nosocomial infection ${ }^{2-4}$.
Gram positive bacteria that normally found in deep areas of skin like sweat glands and hair follicle may survive the heat of initial injury, those heavily colonize the wound within a single post burn day ${ }^{5}$ The frequency of infection by Staphylococcus aureus has increased during the last three decades and their susceptibility pattern have changed. Many strains becoming resistance to the antibiotic of choice and some have even become multi-resistant to three or more classes of antibiotics ${ }^{6}$.

\section{MATERIAL AND METHODS}

This study was conducted between July 2002 to December 2002 at the Department of Microbiology, Basic Medical Sciences Institute, Jinnah Postgraduate Medical Centre, Karachi.

A total of 52 patients with infected burn wound with irrespective of age, sex, while degree and percentage of burn were registered for this study. These patients were admitted since more than last three days of admission in burn unit of 3 different hospitals of Karachi.

A total of 170 burn wound swabs were collected 


\begin{tabular}{|c|c|c|c|c|c|}
\hline Total patients & Total Isolates & Patients infected by S.aureus; & Total S.aureus & Total MSSA & Total MRSA \\
\hline 52 & 190 & $23(44 \%)$ & $41(21.6 \%)$ & $31(76 \%)$ & $10(24 \%)$ \\
\hline
\end{tabular}

following a thorough inspection and examination of an infected area of each patient. These swabs were immersed in Stuart's transport medium, transported to laboratory, cultured on Blood agar, MacConkey's agar and Nutrient agar. Cultured media were incubated at $37^{\circ} \mathrm{C}$ for overnight.

Following incubation isolates of Staph. aureus were identified by their colonial morphology, Gram's staining and were confirmed by certain biochemical tests like Catalase test, Coagulase test (slide and tube method), Mannitol fermentation test and Novobiocin sensitivity test.

According to National Committee for Clinical Laboratory Standards Guidelines, susceptibility test of all isolates of Staph. aureus was performed using different antimicrobial agents by Kirby Bauer method ${ }^{7}$ 8

\section{RESULTS}

Table-I shows the summary of patients,cultures and isolates . Out of total 52 patients $23(44 \%)$ were found infected by S.aureus. Out of 190 isolates 41(21.6\%) were S. aureus in which10 (24\%) were MRSA.

\section{DISCUSSION}

After the initial period of shock, infection is the major complication in burn. Staphylococci were the predominant cause of burn wound infection in pre antibiotic era. It remains an important pathogen at present and is the second most common isolate in burn wound infection ${ }^{9}$.

Staph.aureus is a versatile human pathogen and continues to be an important cause of nosocomial infection. Recently a marked increase in number of

\begin{tabular}{|l|c|c|c|}
\hline \multicolumn{1}{|c|}{$\begin{array}{c}\text { Name of } \\
\text { antibiotic }\end{array}$} & $\begin{array}{c}\text { Disc } \\
\text { content }\end{array}$ & Sensitivity & Resistant \\
\hline Vancomycin & $30 \mu \mathrm{g}$ & $31(100 \%)$ & - \\
\hline Chloramphenicol & $30 \mu \mathrm{g}$ & $31(100 \%)$ & - \\
\hline Imipeneme & $10 \mu \mathrm{g}$ & $29(93.5 \%)$ & $02(06.5 \%)$ \\
\hline Clindamycin & $02 \mu \mathrm{g}$ & $21(67.7 \%)$ & $10(32.2 \%)$ \\
\hline Augmentin & $30 \mu \mathrm{g}$ & $18(58 \%)$ & $13(42 \%)$ \\
\hline Amikacin & $30 \mu \mathrm{g}$ & $17(54.8 \%)$ & $14(45.2 \%)$ \\
\hline Cephalothin & $30 \mu \mathrm{g}$ & $24(77.5 \%)$ & $07(22.5 \%)$ \\
\hline Gentamycin & $10 \mu \mathrm{g}$ & $03(9.6 \%)$ & $28(90.3 \%)$ \\
\hline Ciprofloxacin & $05 \mu \mathrm{g}$ & $02(06.5 \%)$ & $29(93.5 \%)$ \\
\hline Cefuroxime & $30 \mu \mathrm{g}$ & $18(58 \%)$ & $13(42 \%)$ \\
\hline Amoxacillin & $10 \mu \mathrm{g}$ & $03(9.6 \%)$ & $28(90.3 \%)$ \\
\hline Clarithromycin & $15 \mu \mathrm{g}$ & $14(45.2 \%)$ & $17(54.8 \%)$ \\
\hline
\end{tabular}

Table-ll. Sensitivity pattern of 31 isolates of methicillin sensitive S.aureus

\begin{tabular}{|l|c|c|c|}
\hline \multicolumn{1}{|c|}{$\begin{array}{c}\text { Name of } \\
\text { antibiotic }\end{array}$} & $\begin{array}{c}\text { Disc } \\
\text { Content }\end{array}$ & Sensitivity & Resistant \\
\hline Vancomycin & $30 \mu \mathrm{g}$ & $10(100 \%)$ & - \\
\hline Chloramphenicol & $30 \mu \mathrm{g}$ & $10(100 \%)$ & - \\
\hline Clindamycin & $02 \mu \mathrm{g}$ & $04(40 \%)$ & $06(60 \%)$ \\
\hline Clarithromycin & $15 \mu \mathrm{g}$ & $02(20 \%)$ & $08(80 \%)$ \\
\hline Gentamycin & $10 \mu \mathrm{g}$ & $02(20 \%)$ & $08(80 \%)$ \\
\hline Amikacin & $30 \mu \mathrm{g}$ & $01(10 \%)$ & $09(90 \%)$ \\
\hline Ciprofloxacin & $05 \mu \mathrm{g}$ & - & $10(100 \%)$ \\
\hline \multicolumn{2}{|c|}{ Table-III. Sensitivity pattern of (n=10) isolates of } \\
methicillin resistant Staph;. Aureus
\end{tabular}


hospital infection due to MRSA has been reported in many countries ${ }^{10}$.

The prevalence of MRSA infection varies widely from one geographical location to another, from hospital to hospital and over time. Once a clone of MRSA is introduced into a hospital it can spread, causing outbreaks ${ }^{6}$.

In present study the prevalence of Staph.aureus was $21.6 \%$ in burn wounds of patients, that is in accordance with several studies ${ }^{8,11-14}$. This prevalence of Staph.aureus was relatively higher than the other studies $^{9-15}$ where it was ranging $9-14 \%$. This prevalence of Staph.aureus was markedly lower than the studies conduced by Edward and Greenwood $(2003)^{16}$, Appelgren et al (2002) ${ }^{17}$ and Nakhla and Sanders $(1991)^{18}$ where it was ranging from $69 \%$ to $75 \%$.

Knowledge of the organisms colonizing a wound will prove useful in choosing an antibiotic regimen, while awaiting definitive result of wound cultures ${ }^{19}$.

Since 1980 Vancomycin has been uniformly effective antibiotic available for serious Staphylococcal infection. The laboratory reports of low susceptibility or partial resistance of MRSA to Vancomycin was $1.4 \%$ in burn wound infection in 1993 , that act as a warning and suggested the possibility of developing total resistance in near future, but it can not be labeled as Vancomycin resistant ${ }^{10}$.

In present study Vancomycin and Chloramphenicol was the highly (100\%) effective drugs against Staph. aureus that is in accordance with other studies Song et al $(2001)^{20}$ and Revathi et al (1998) ${ }^{21}$.

Imipenem showed high activity rate $(93 \%)$ while Cephaloxin and Clindamyin were moderately active (67\% and $62 \%$ respectively) while only $43 \%$ strains were sensitive to Amikacin in present study.
Amoxicillin, Ciprofloxacin and Gentamycin were highly ineffective (88-95\%) against Staph.aureus while Clarithromycin, Cefuraxime, Amikacin and Augmentin were moderately inactive (50-59\%) against these organisms that is in accordance with other studies ${ }^{20-21}$.

Antimicrobial drugs shows less effectiveness after the arising of resistance mechanism in clinical prevalent pathogens ${ }^{22}$.

There is no antimicrobial to which resistance had not eventually appeared ${ }^{23}$. Bacterial resistance to antimicrobial agents is an important public health problem in both the developing and the developed countries, in which many of these organisms are multiple drug resistant i.e., resistant to two or more antibiotics to which the bacteria was usually susceptible $^{24}$.

High frequency and nature of antibiotic resistance may be due to over usage of commonly used antibiotics such as Ciprofloxacin, Gentamicin and Amikacin as well unavailability and high cost of preferred antibiotics of choice? .

\section{CONCLUSIONS}

Normal skin is effective barrier that prevent penetration of surface bacteria. The devitalized tissue and moist burn is favorable for colonization and proliferation of micro-organisms and subsequent infection, therefore the potential risk of burn wound sepsis persist until complete wound healing.

Gram positive bacteria found in the depth of sweat glands and hair follicle may remain alive following the heat of initial injury, these bacteria heavily colonize the wound at initial days following injury. Once Staph aureus specially MRSA establishing in burn unit, it is very difficult to eradicate these bacteria from burn unit. It is therefore all efforts must made to prevent burn patients from infection specially Staph. Aureus by establishing infection control unit in these burn units. 


\section{Copyright@ 04 Dec, 2012.}

\section{REFERENCES}

1. Proksch E, Brandner JM, Jensen JM. The skin: an indispensable barrier. Exp Dermatol. 2008 Dec;17(12):1063-72.

2. Gang RK, Bang RL, Sanyal SC, Mokaddas E, Lari AR. Pseudomonas aeruginosa septicaemia in burns. Burns 1999; 25: 611-616.

3. Pallua N, Fuchs PC, Hafemann B, Volpel U, Noah M, Lutticken R. A new technique for quantitative bacterial assessment on burn wounds by modified dermabrasion. J Hosp Infect 1999; 42: 329-337.

4. Camilleri IG, Pedler SJ, Murphy 0, Reid CA. Cross infection on combined Paediatric Plastic Surgery and Burns Unit: A clinical and micrbiological audit. Burns 1999; 25: 655-658.

5. Deirdre Church, Sameer Elsayed, Owen Reid, Brent Winston, Robert Lindsay (2006). Burn Wound Infections. Clin Microbiol Rev. April; 19(2): 403-434.

6. Mokaddas EM, Sanyal SC. Resistance pattern of Pseudomonas aerugonisa to carbapeneme and piperacillin. J Chemother 1999; 11(2): 93-96.

7. NCCLs Performance of standard for antimicrobial susceptibility testing; eighth international supplement, 1998; 18(1):100-513.

8. Fuchs PC, Kopp J, Hafner H, Kleiner U and Pallua N. MRSA retrospective analysis of an outbreak in the burn center Aachen. Burns 2002;28(6):575-578.

9. Lari AR and Alaghebandan R. Nasocomial infections in an Iranian burn care center. Burns 2000;26(8):737740 .

10. Prasanna M and Thomas C. A profile of methicillin resistant Staphylococcus aureus infection in the burn center of the Sultanate of Oman. Burns1999; 24(7): 631-636.

11. Singh NP, Goyal R, Manchanda V, Das S, Kaur I and Talwar V. Changing trends in bacteriology of burns in the burns unit, Delhi, India. Burns 2003; 29(2):129132.
12. Oraloncul, Yuksel F, Altunay H, Acikel C, Celikoz B, Cavulu A. (2002). The evaluation of nasocomial infection during 1 year period in the burn unit of a training hospital in Istanbul, Turkey. Burns 2003; 28(8): 738-744

13. Santucci SG, Gobara S, Santos CR, Fontana C, Levin AS. Infections in a burn intensive care unit: Experience of seven years. J Hosp Infect2003; $53(1): 6-13$.

14. Nasser S, Mabrouk A, Maher A. Colonization of burn wounds in Ain Shams University Burn Unit. Burns. May;2003;29(3):229-33.

15. Nasser S, Mabrouk A and Maher A. Colonization of burn wounds in Ain Shams University Burn Unit. Burns 2003; 29(3): 229-233.

16. Edwards V, Greenwood J. (2003) What's new in burn microbiology? James Laing Memorial Prize Essay 2000. Burns 2003;29(1):15-24.

17. Appelgren P, Bjornhagen V, Bragderyd K, Jonsson CE, Ransjo U. (2002). A prospective study of infections in burn patients. Burns2003;28(1):39-46.

18. Carlene A. Muto, MD, MS; John A. Jernigan, MD, MS; Belinda E. Ostrowsky, MD, MPH; Hervé M. Richet, MD; William R. Jarvis, MD; John M. Boyce, MD; Barry M. Farr, MD, MSc. (2003) SHEA Guideline for Preventing Nosocomial Transmission of Multidrug-Resistant Strains of Staphylococcus aureus and Enterococcus. Infection control and hospital epidemiology. Vol. 24 No. 5362-386.

19. Dodd D, Stutman HR. Current issue in burn wound infections. Adv Pediatr Infect Dis 1991; 6:137-162.

20. Kaleem F, Usman J, Hassan A, Omair M, Khalid A, Roz Uddin. Sensitivity pattern of methicillin resistant Staphylococcus aureus isolated from patients admitted in a tertiary care hospital of Pakistan. IRAN. J. MICROBIOL. 2010;2(3):141-143.

21. Revathi G, Puri J and Jain BK. Bactriology of burns. Burns1998; 24(4):347-349.

22. Jones RN, Pfaller MA, Doern GV, Erwin ME and Hollis $\mathrm{RJ}$, the Cefepime study group. Antimicrobial activity and spectrum investigation of eight broad spectrum 
Beta lactam Drugs: A 1997 Surveillance Trial in 102. Medical Centres in the United States. Diagnostic Microbiol Infec Dis 1998;30(3): 215-0228.

23. Neely AN and Holder IA. Antimicrobial resistance. Burns 1999; 25(1): 17-24.
24. H.H.S. Gov. US department of health and human services2010 \{online). Thomas R. Frieden Antibiotic Resistance and the Threat to Public Health. http://www.hhs.gov/asl/testify/2010/04/t20100428b. html.

\section{AUTHOR(S):}

1. DR. ZULFIQAR ALI NAQVI

Dewan Medical and Dental College

Karachi

2. DR. QAMAR AZIZ

Baqai Medical College, Karachi

3. DR. ARIF MEMON

Jinnah Medical College, Karachi
Correspondence Address:

Dr Zulfiqar ali Naqvi

Dewan Medical and Dental college

Karachi

drwa65@yahoo.com

Article received on: $12 / 07 / 2012$ Accepted for Publication: $\quad$ 04/12/2012 Received after proof reading: 10/12/2012

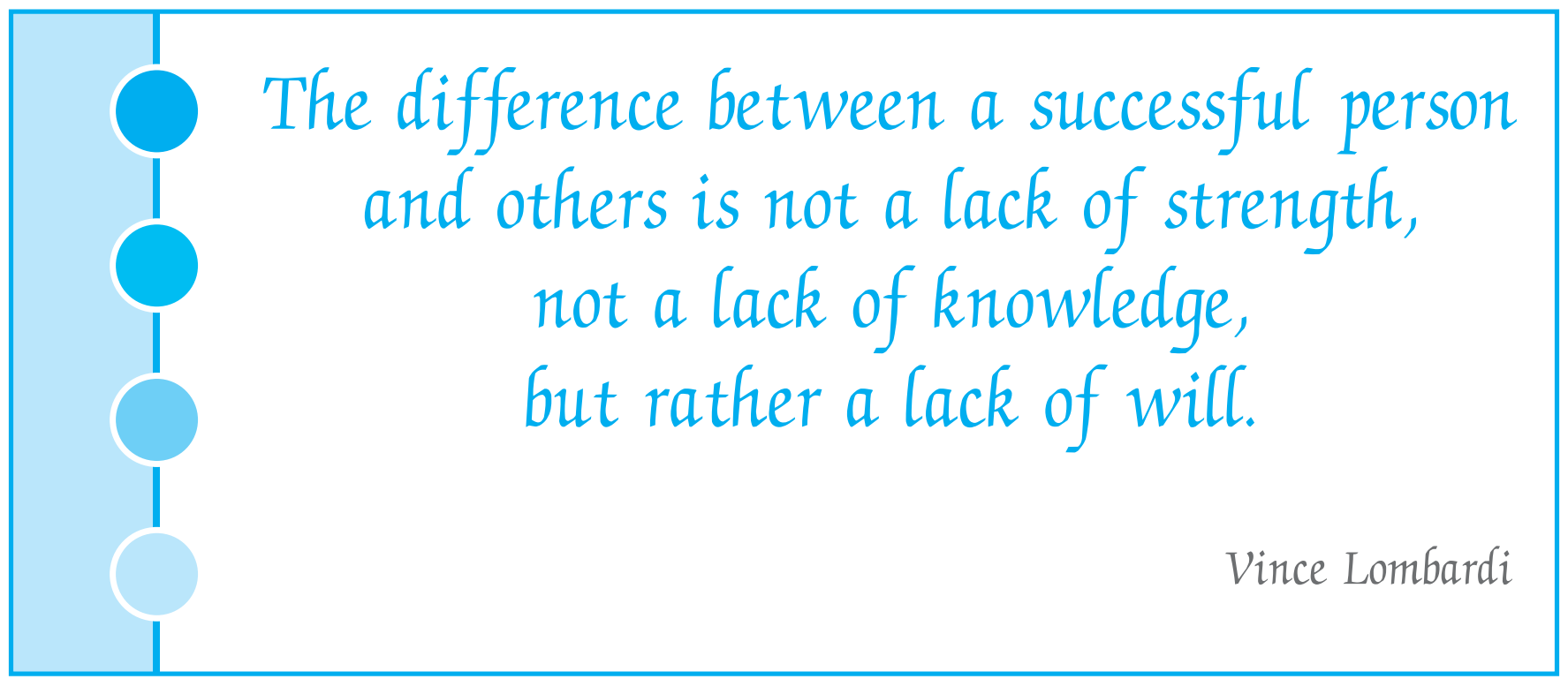

